\title{
Crashworthiness of Magnesium Sheet Structures
}

\author{
D. Steglich ${ }^{1, a}$, J. Bohlen ${ }^{2, b}$, X. Tian ${ }^{1 . c}$, S. Riekehr ${ }^{1, d}$, N. Kashaev ${ }^{1, e}$, \\ S. Bargmann ${ }^{1,3, f}$, D. Letzig ${ }^{2, g}$, K.U. Kainer ${ }^{2, h}$ and N. Huber ${ }^{1, i}$ \\ ${ }^{1}$ Helmholtz-Zentrum Geesthacht, Institute of Materials Research, Materials Mechanics / \\ ACE-Centre, Max-Planck-Str. 1, D-21502 Geesthacht, Germany \\ ${ }^{2}$ Helmholtz-Zentrum Geesthacht, Institute of Materials Research, Magnesium Innovations Centre \\ MagIC, Max-Planck-Str. 1, D-21502 Geesthacht, Germany \\ ${ }^{3}$ Institute of Continuum and Material Mechanics, Hamburg University of Technology (TUHH), \\ Eißendorfer Str. 42, D-21703 Hamburg \\ adirk.steglich@hzg.de, bjan.bohlen@hzg.de, 'xiaowei.tian@hzg.de, d'stefan.riekehr@hzg.de, \\ enikolai.kashaev@hzg.de, 'swantje.bargmann@hzg.de, ${ }^{\mathrm{g}}$ dietmar.letzig@hzg.de, \\ harl.kainer@hzg.de, 'nobert.huber@hzg.de
}

Keywords: Magnesium sheet alloys, Finite element analysis, Uniaxial compression, Buckling

\begin{abstract}
A hollow rectangular profile, as an example of a typical structural component made of magnesium alloy sheets has been built, tested and evaluated in order to assess its behaviour during axial crushing. The profiles were joined from plane sheets of AZ31 and ZE10, respectively, by laser beam welding and were then tested in compression. Numerical simulations have been conducted to understand the complex interplay between hardening characteristics of the materials under investigation, profile cross-section variation and energy absorption. The results from the compression testing of the profiles show that the welds are not the source of damage initiation and failure. The performance of the magnesium profiles in terms of dissipated specific energy is confirmed for small and intermediate displacements to be comparable to that of aluminium profiles. For large displacements, however, the shear-type failure mode of magnesium causes a sharp drop of the crushing force and thus limits the energy absorption. These findings demonstrate the requirement for an alloy and wrought magnesium process development specifically for crash applications which aims at progressive hardening along with high ductility for improving the bending and shear behaviour.
\end{abstract}

\section{Introduction}

Magnesium alloys appear to be attractive for transport applications due to their high specific strength compared to steels. For structural components in passenger cars in general, manufacturers have to prove energy absorption and structural integrity in case of crash scenarios. Several criteria are used to assess crashworthiness, including the deformation pattern of the vehicle sub-structure, the acceleration experienced by the vehicle during impact, and the probability of injury predicted by human body models. Much is known about the deformation behaviour of aluminium and steel structures.

However, magnesium and its alloys recently came into focus. Depending on the processing route of the alloy (cast or wrought material), the mechanical behaviour can be significantly different from that observed in classical structural metals. While in case of cast alloys the elasto-plastic response is primarily isotropic, in rolled sheets or extruded rods the crystallographic texture causes different yielding in tension and compression, which is referred to as the strength differential (SD) effect [1]. Because of their improved ductility, wrought alloys are preferred for structural components. Thus, any analysis of the crushing and buckling behaviour of profiles obviously has to incorporate the different characteristic in tension and compression.

Recent contributions in this field address the failure pattern of extruded magnesium rods [2], the strain rate sensitivity in compression [3,4], the behaviour of cast alloys [5] and FE-modelling of the response during crushing [6]. Most of the investigations mentioned were conducted at room 
temperature. Incorporation of the anisotropy to the material model is documented for aluminium [7], but not yet for magnesium alloys.

In a cooperation between the Light-weight Materials Assessment, Computing and Engineering Centre (ACE) and the Magnesium Innovation Centre (MagIC), both at Helmholtz-Zentrum Geesthacht, an attempt was made to study the crashworthiness of prismatic profiles produced from magnesium alloys AZ31 and ZE10 under quasistatic macroscopic compressive loading. The results were compared with predictions from finite element simulations as well as with experimental results achieved with an aluminium 6060 profile as reference.

\section{Mechanical Characterisation}

The material analyzed was rolled magnesium sheet with $2 \mathrm{~mm}$ nominal thickness in a stress-relieved O-temper condition. The material was obtained commercially from former Salzgitter Magnesium Technology (SZMT) of Salzgitter and is therefore consistent with regards to the production method used. Uniaxial tensile tests and compression tests were conducted on the two sheets along the rolling (RD) and the transverse direction (TD). All of the tests were quasistatic tests conducted at room temperature. For the uniaxial tensile test, dimensions specified in the international standard DIN 50125 were used. The tensile tests were performed in universal materials tester Zwick Z050. Fig. 1 shows the true stress-strain curves obtained by the tensile tests.
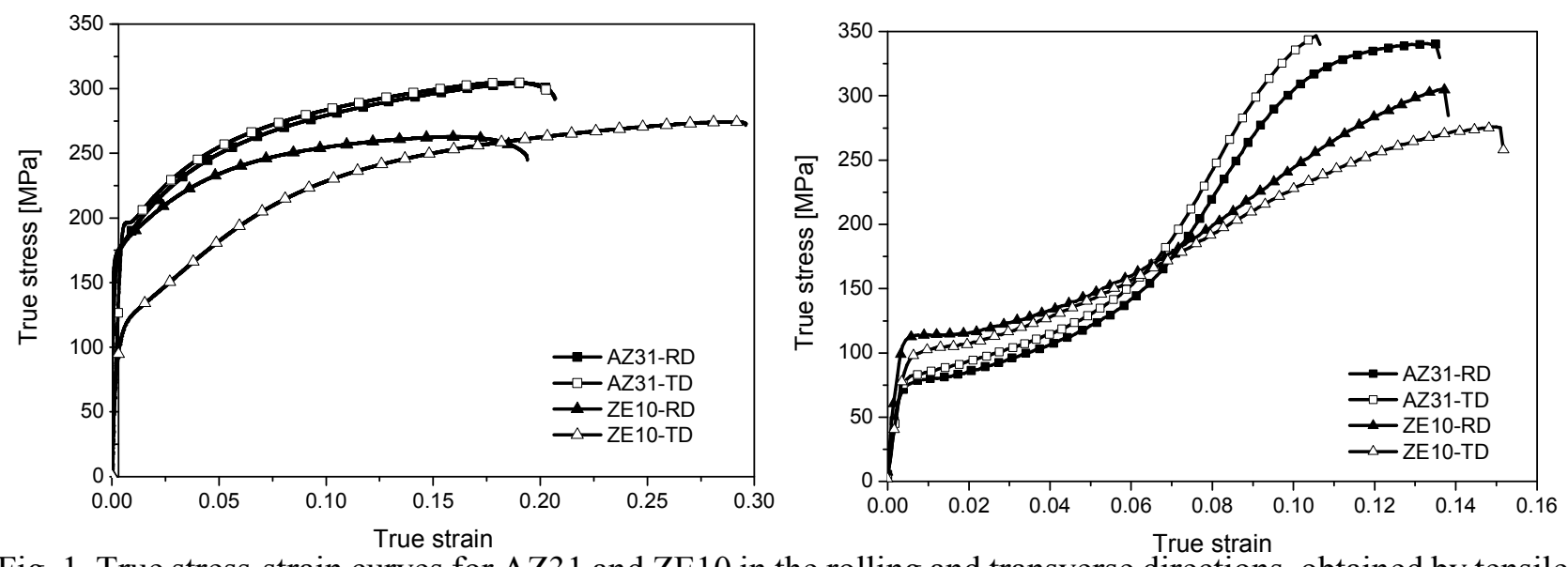

Fig. 1. True stress-strain curves for AZ31 and ZE10 in the rolling and transverse directions, obtained by tensile tests (left) and by compression tests (right) at room temperature.

Methods for large-strain in-plane compression testing of sheet materials remain more challenging; buckling occurs easily preventing uniaxial deformation. Therefore, cubic specimens of 5 glued layers of magnesium sheets were prepared for the tests. The dimensions of the specimen were $10 \times 10 \times 10 \mathrm{~mm}^{3}$. The testing machine used in the tests was a SCHENCK servo-hydraulic $1000 \mathrm{kN}$ machine.

A compressive force was applied along in plane direction of the sheet and the displacement between the top and bottom surfaces of the specimen was recorded by an extensometer. The true stress-strain curves of the compression tests are shown in the right hand part of Fig. 1. For AZ31 the hardening rate along TD is higher compared to ZE10 for both, tension and compression tests. The difference between the two orientations in the tensile test is pronounced in the case of ZE10. It is worth noting that both magnesium alloys reveal the "S" shape hardening during compression tests.

\section{Laser Welding of Profiles}

Square tubes with outer dimensions $50 \mathrm{~mm} \times 50 \mathrm{~mm}$ and $400 \mathrm{~mm}$ in length were produced from AZ31 and ZE10 sheets. Welding was performed using a $3.3 \mathrm{~kW} \mathrm{Nd:YAG} \mathrm{laser} \mathrm{with} \mathrm{a} \mathrm{fibre-optic}$ (400 $\mu \mathrm{m}$ core diameter) and a $200 \mathrm{~mm}$ focal length. The laser optic was mounted on a KUKA KR30HA industrial robot. The clamping system was based on a magnetic system with 7 magnets of 
$250 \mathrm{~N}$ each (Fig. 2a). All specimens were tack welded on all seams before final welding. Laser welding without filler wire was developed and optimized with regard to the microstructural and mechanical performance of the joints. The welding parameters were set to a laser power of $2.8 \mathrm{~kW}$ at a focus position of $-0.3 \mathrm{~mm}$ in $\mathrm{x}$ and $\mathrm{z}$ direction. Welding was carried out at a welding speed of $3.6 \mathrm{~m} / \mathrm{min}$ under shielding gas (surface: Ar at $20 \mathrm{1} / \mathrm{min}$; root: $\mathrm{He}$ at $20 \mathrm{l} / \mathrm{min}$ ). Details on microstructure and mechanical properties of the laser beam welded magnesium alloys can be found in [8]. All of the welded tubes were non-destructively inspected by X-ray radiography. With the chosen laser welding parameters joints with a low porosity were produced. All joints showed the typical key-hole welding effect of narrow welds (Fig. 2b-c). No heat-affected zone was observed.

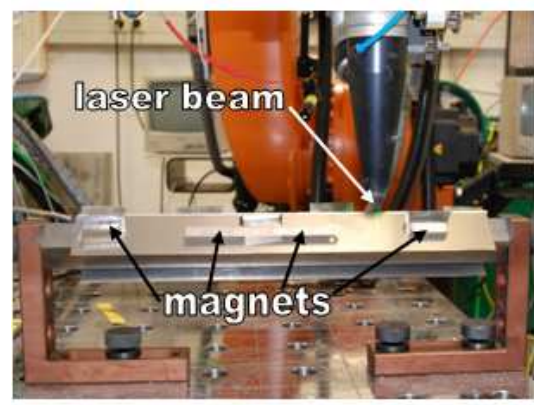

(a)

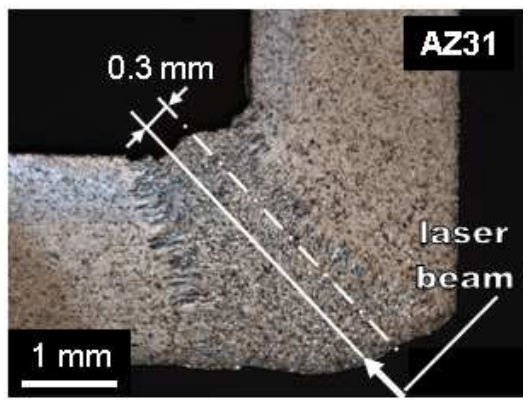

(b)

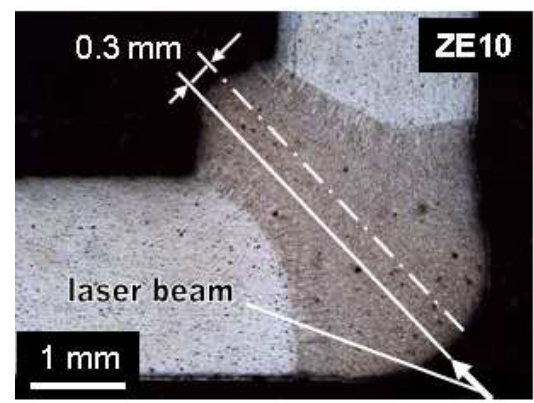

(c)

Fig. 2. Photograph of the clamping system for laser welding of Mg-sheets (a); micrograph of the AZ31 ridge weld (b) and micrograph of the ZE10 ridge weld (c).

\section{Crush Test Results and Simulations}

Axial crush tests were performed after clamping the ends of the profiles to studs. The upper transverse was moved downwards with a speed of $10 \mathrm{~mm} / \mathrm{min}$. The axial reaction force was recorded as a function of the transverse travel. Each specimen was loaded until local cracking was observed, which coincides with a sharp drop of the reaction force. Fig. 3 shows the measured force-displacement records of rectangular hollow profiles for the two materials, namely AZ31 and ZE10. The peak load in the early stage of deformation corresponds to homogenous deformation prior to buckling. With the onset of buckling the load decreases reaching a plateau during the formation of buckles. In the case of AZ31 the force increases before failure, while this was not observed for ZE10. Cracks appeared in the base material in the vicinity of the profile's edges.

In the past, explicit finite element crashworthiness codes became an indispensable tool for the design of energy absorbing elements. In this work only quasi-static events are considered and computationally efficient implicit simulations were performed. The profiles were meshed using 4-noded linear shell elements with 21 section points through the thickness without explicitly considering the weld zone. Displacement boundary conditions were prescribed at the ends of the profiles, the resulting reaction forces were compared with their counterparts recorded during the crush tests. An elastic-plastic material law [9] was adopted, which was calibrated using the stress-strain curves shown in Fig. 1. Failure was described by means of a strain-based criterion [10]. Results of the simulations are presented together with the experiments in Fig. 3. They show a reasonably good agreement with the tests. The predictions of the deformed configurations are included in the figure evidencing the difference in buckling mode between the two materials.

Significant differences in terms of buckling pattern and failure mode were furthermore recorded between the two magnesium alloys and an aluminium 6060 profile of identical geometry, which was considered as a reference. In the case of the latter, folds develop subsequently during crushing leading to an accordion-like pattern, see Fig. 4. Small cracks initiate but do not breach the profiles integrity. Therefore, the achieved displacement is higher than those of the magnesium alloys (Figs. $3 \& 4$.). 

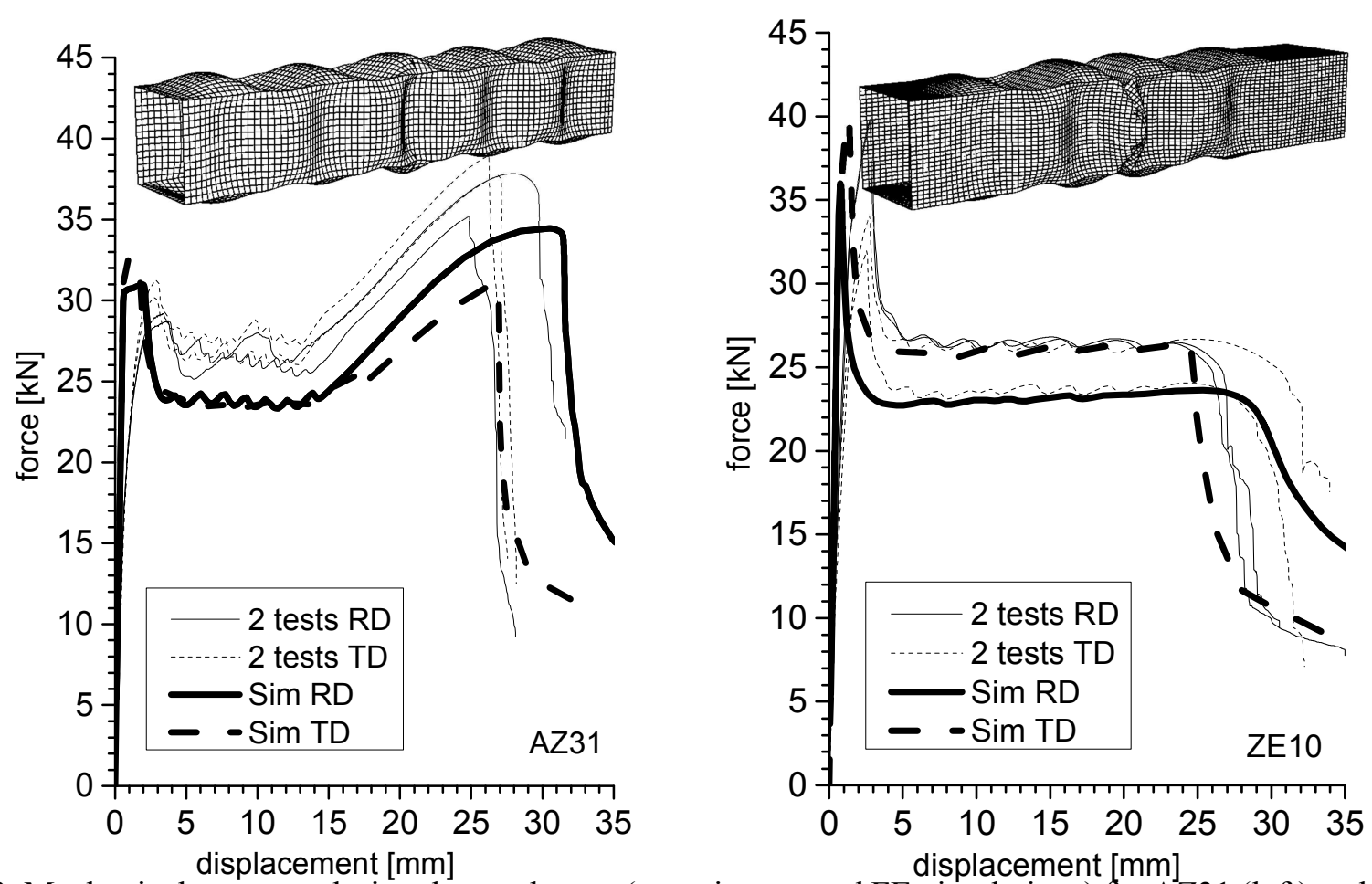

Fig. 3. Mechanical response during the crush tests (experiments and FE-simulations) for AZ31 (left) and ZE10 (right).
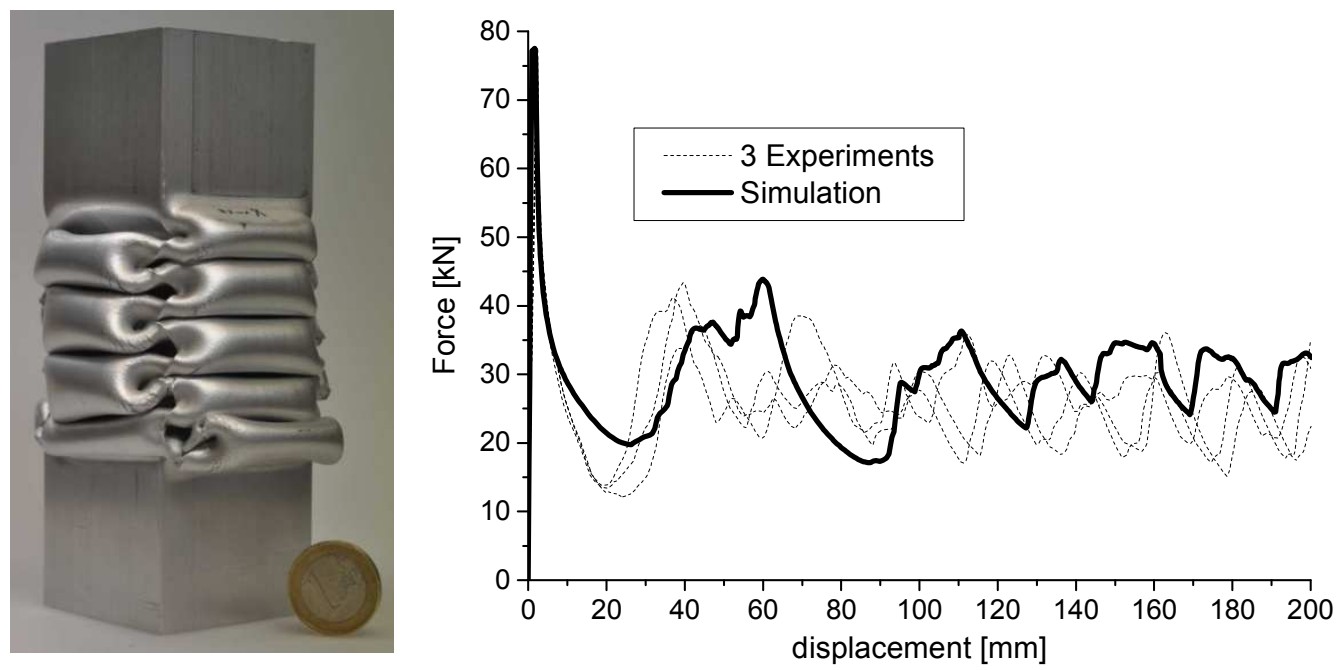

Fig. 4. Folding pattern (left) and force-displacement record (right) obtained for the reference alloy A16060 (experiments and FE-simulation).

\section{Conclusions}

Buckling and failure modes for magnesium profiles were identified as being different from those observed for an identical aluminium profile. The microscopic fracture mode for both magnesium alloys was identified to be shear failure over the sheet's thickness in the base material. While aluminium alloys usually exhibit progressive folding, the tested magnesium profiles, however, showed simultaneous formation of folds. This is related to the high tangent modulus in compression. This effect - even more pronounced in AZ31 than in ZE10 - results in good energy absorption, see Fig. 1. For compression of the profiles up to $20 \mathrm{~mm}$ the specific dissipated energy was $2.07 \mathrm{~J} / \mathrm{g}$ in the case of AZ31 and $2.25 \mathrm{~J} / \mathrm{g}$ in the case of ZE10, while in the reference aluminium alloy 6060 a specific energy of only $1.81 \mathrm{~J} / \mathrm{g}$ was dissipated. This positive trend is inverted once a larger displacement of e.g. $200 \mathrm{~mm}$ is considered. In this case all magnesium profiles were completely fractured, while the aluminium profile was only partially fractured and could still transfer non-zero axial load. 
The frequently reported good specific strength of magnesium alloys induces an energy absorption superior to that of aluminium alloy once small and intermediate deformations are considered. A high hardening rate is beneficial for energy absorption as long as no fracture occurs. Thus, further alloy development for crash applications should aim at combining both, progressive hardening and improved ductility in compression.

\section{Acknowledgements}

The authors like to thank Rene Dinse, Kay Erdmann, Julia Hapke, Jürgen Knaack, Stefan Koch, Emma Morales and Gert Wiese for their kind technical support during specimen fabrication, experimentation and for conducting metallographic investigations.

\section{References}

[1] W.F. Hosford, T.J. Allen, Twinning and directional slip as a cause for a strength differential effect, Metall. Trans. 4 (1973) 1424-1425.

[2] P.D. Beggs, W. Song, M. Easton, Failure modes during uniaxial deformation of magnesium alloy AZ31B tubes, Int. J. Mech. Sciences 52 (2010) 1634-1645.

[3] D. Hasenpouth, C. Salisbury, A. Bardelcik, M.J. Worswick, Constitutive behaviour of magnesium alloy sheet at high strain rates, in: Dymat 2009: 9th Int. Conf. on Mechanical and Physical Behaviour of Materials under Dynamic Loading, Vol 2. Cedex A: E D P Sciences, 2009, pp. 1431-1435.

[4] I. Ulacia, C.P. Salisbury,I. Hurtado, M.J. Worswick, Tensile characterization and constitutive modeling of AZ31B magnesium alloy sheet over wide range of strain rates and temperatures, $\mathrm{J}$. Mater. Process. Tech. 211 (2011) 830-839.

[5] X.M. Chen, S.R. Wu, D.A. Wagner, W.R. Hu, Study of die cast magnesium components for crash safety, Int. J. Crashworthiness 7 (2002) 429-440.

[6] F. Zhu, C.C. Chou, K.H. Yang, X. Chen, D. Wagner, S. Bilkhu, Application of AM60B magnesium alloy material model to structural component crush analysis, Int. J. Vehicle Safety 6 (2012) 178-190.

[7] B.W. Williams, C.H.M. Simha, N. Abedrabbo, R. Mayer, M.J. Worswick, Effect of anisotropy, kinematic hardening, and strain-rate sensitivity on the predicted axial crush response of hydroformed aluminium alloy tubes, Int. J. Impact Engrg. 37 (2010) 652-661.

[8] S. Riekehr, V. Ventzke, M. Horstmann, N. Kashaev, Fatigue and fatigue crack propagation of Nd:YAG laser beam-welded magnesium AZ31-HP sheet material, in: Mg2012: Proceedings of the 9th International Conference on Magnesium Alloys and their Applications. 2012, pp. 827-832

[9] R. Hill, A theory of the yielding and plastic flow of anisotropic metals, Proc. Roy. Soc. Lond. A 193 (1948) 281-297.

[10] H. Hooputra, H. Gese, H. Dell, H. Werner, A comprehensive failure model for crashworthiness simulation of aluminium extrusions, Int. J. Crashworthiness 9 (2004) 449-463. 